\title{
Antibiotics in malaria therapy: which antibiotics except tetracyclines and macrolides may be used against malaria?
}

\author{
Tiphaine Gaillard ${ }^{1,2,3}$, Marylin Madamet ${ }^{2,3,4}$, Francis Foguim Tsombeng ${ }^{2,3}$, Jérôme Dormoi ${ }^{2,3}$ \\ and Bruno Pradines $2,3,4^{*}$
}

\begin{abstract}
Malaria, a parasite vector-borne disease, is one of the most significant health threats in tropical regions, despite the availability of individual chemoprophylaxis. Malaria chemoprophylaxis and chemotherapy remain a major area of research, and new drug molecules are constantly being developed before drug-resistant parasites strains emerge. The use of anti-malarial drugs is challenged by contra-indications, the level of resistance of Plasmodium falciparum in endemic areas, clinical tolerance and financial cost. New therapeutic approaches are currently needed to fight against this disease. Some antibiotics that have shown potential effects on malaria parasite have been recently studied in vitro or in vivo intensively. Two families, tetracyclines and macrolides and their derivatives have been particularly studied in recent years. However, other less well-known have been tested or are being used for malaria treatment. Some of these belong to older families, such as quinolones, co-trimoxazole or fusidic acid, while others are new drug molecules such as tigecycline. These emerging antibiotics could be used to prevent malaria in the future. In this review, the authors overview the use of antibiotics for malaria treatment.
\end{abstract}

Keywords: Antibiotics, Malaria, Plasmodium falciparum, Anti-malarial drug, Resistance, Prophylaxis, Treatment

\section{Background}

Malaria in one of the most significant health threats in tropical regions with high morbidity and mortality rates. In 2015, approximately 3.2 billion people-nearly half of the world's population-were at risk of malaria [1]. According to the latest WHO estimates, released in December 2015, there were 214 million cases of malaria in 2015 and 438,000 deaths. Sub-Saharan Africa continues to carry a disproportionately high share of the global malaria burden. In 2015, the region was home to $88 \%$ of malaria cases and $90 \%$ of malaria deaths. Despite the availability of chemotherapy and chemoprophylaxis, the disease remains an important public health problem in many countries. The spread of anti-malarial drug

\footnotetext{
*Correspondence: bruno.pradines@gmail.com

${ }^{2}$ Unité de Parasitologie et d'Entomologie, Département des Maladies Infectieuses, Institut de Recherche Biomédicale des Armées, Marseille, France

Full list of author information is available at the end of the article
}

resistance from Southeast Asia to Africa has previously happened with chloroquine and sulfadoxine-pyrimethamine $[2,3]$. To overcome this problem new therapeutic strategies are been developed. Many other drugs formulations have recently been developed such as combination of molecules (artemisinin-based combination therapy) [4] and use of antibiotics that have been shown to be effective against malaria parasites $[5,6]$.

This literature review focused on the use of antibiotics for malaria chemoprophylaxis and treatment. The term of antibiotic in this review defined any compound that has been used to treat bacterial infections and their analogues developed if there were active against Plasmodium falciparum. Two families, tetracyclines and macrolides and their derivatives, have been the focus of many studies in the past 30 years and were previously described in two reviews $[5,6]$. However, other antibiotics against malaria parasites could be developed in the future. This third and final review on the use of antibiotics as anti-malarial drugs described the activity against $P$. falciparum of 
co-trimoxazole, quinolones, tigecycline, mirincamycin, ketolides, fusidic acid and thiopeptides.

\section{Co-trimoxazole}

Co-trimoxazole is a combination of trimethoprim and sulfamethoxazole. Trimethoprim is derived from pyrimidine and belongs to a group of compounds well characterized for their antibacterial activity. Trimethoprim inhibits the enzyme dihydrofolate reductase, and has been shown to act as a sulfonamide potentiator [7]. In 1971, a combination of trimethoprim and sulfamethoxazole was reported to be effective in the treatment of malaria infections in semi-immune Nigerian children [8]. Additionally, co-trimoxazole prophylaxis is currently recommended by the World Health Organization (WHO) to prevent opportunistic infections in HIV infected persons [9]. Considering the reports on the impact of co-trimoxazole on malaria, both in HIV-infected and healthy individuals, the efficacy of this drug was studied for a potential use in both prophylaxis and treatment of malaria $[10,11]$. It appears that co-trimoxazole could be an alternative for malaria treatment. Additionally, cotrimoxazole could also be a good alternative in malaria prophylaxis for different target groups, including children and adults, HIV positive or negative patients and pregnant women [12-15]. Daily use of co-trimoxazole during pregnancy had similar effects as intermittent preventive treatment (IPT) in terms of preterm deliveries, stillbirths, neonatal deaths, spontaneous abortions or birth weights [14]. Co-trimoxazole is effective (above 90\%) for uncomplicated malaria treatment in children in areas of high endemicity [12, 16-18]. However, co-trimoxazole had no gametocytocidal effect in vivo $[8,15]$ and neither trimethroprim nor sulfamethoxazole have action in vitro against early and late stage gametocytes [19]. Additionally, the use of this combination in non-pregnant HIVinfected patients reduced the risk of malaria incidence in children and adults in Africa [20-25]. In Uganda, despite the high rates of antimicrobial resistance to co-trimoxazole, its use in non-pregnant HIV-infected patients reduced the risk of mortality by $46-63 \%$ and was associated to lower rates of malaria infection [23, 24]. In a study assessing the prophylaxis effect of co-trimoxazole, its use in combination with insecticide-treated bed nets reduced the risk of malaria incidence by at least $95 \%[13,22]$. The same result was observed in Mali within non-pregnant HIV-negative population with a protective efficacy of 99.5 and $97 \%$ in symptomatic and asymptomatic populations, respectively [26]. In an area with high malaria transmission rate and high antifolate resistance such as Uganda, daily prophylaxis with co-trimoxazole yielded a $39 \%$ reduction of malaria incidence in children [27]. During pregnancy, malaria prophylaxis with co-trimoxazole reduced malaria incidence in HIV-pregnant women as well as the prevalence of placental malaria $[28,29]$. Similar results were observed among HIV-infected pregnant women on neonatal mortality in Zambia (from 9 to $0 \%$ ) [30].

Concerning the resistance to co-trimoxazole, some studies have shown evidence of cross-resistance between co-trimoxazole and sulfadoxine-pyrimethamine [31, 32]. However, co-trimoxazole remains effective in areas with high antifolate resistance, and it seems not to be associated with a higher prevalence of mutations related to antifolate resistance [21, 27, 33]. The use of co-trimoxazole as prophylaxis in HIV-infected patients did not show any selection of resistant $P$. falciparum parasites to sulfadoxine-pyrimethamine among HIV-uninfected household members [34]. Data from another study conducted in Kenya have shown that the daily use of co-trimoxazole prevented malaria and reduced the prevalence of resistant $P$. falciparum parasites to sulfadoxine-pyrimethamine despite the fact that it increased pneumococcus and Escherichia coli resistance [35].

Additionally, co-trimoxazole is inexpensive, almost universally available and has a wide clinical spectrum of activity against bacteria, fungi and protozoan infections [36]. Co-trimoxazole could be an alternative for IPT, but not associated with sulfadoxine-pyrimethamine. Indeed, in HIV-infected women, IPT by sulfadoxinepyrimethamine is contraindicated to avoid the potentially serious drug interactions with co-trimoxazole, which is currently recommended in all HIV-infected pregnant women to prevent opportunistic infections. The paradox is that HIV-infected women who are the most vulnerable to malaria infection cannot be treated with sulfadoxine-pyrimethamine as IPT, even if the use of sulfadoxine-pyrimethamine is a life-saving and highly costeffective intervention [37]. However, most information available on co-trimoxazole comes from Africa; more randomized controlled trials, including trials from other areas, are needed to evaluate the efficacy and the safety of co-trimoxazole.

\section{Anti-malarial quinolones}

Quinolones are synthetic compounds mostly used as antibiotics for their bactericidal properties. Quinolones contain the 4-oxo-1,4-dihydroquinoline skeleton. The first antibacterial quinolone, nalidixic acid, was discovered as a by-product during the synthesis of chloroquine [38]. The quinolone scaffold is present in the structure of compounds that display anti-malarial activity, probably by targeting the gyrase enzyme of the parasites, a type II topo-isomerase [39]. However, in P. falciparum there is evidence for off-target toxicity, particularly for ciprofloxacin [40]. The main quinolones used as antibiotics 
are fluoroquinolones. Their anti-malarial activity has been documented [41]. Norfloxacin, ofloxacin, pefloxacin and trovafloxacin displayed low in vitro anti-malarial activity in the micromolar range against $P$. falciparum $(20->100 \mu \mathrm{M})$ [42-46]. Many studies have shown that ciprofloxacin displayed the best in vitro anti-malarial activity within the first $48 \mathrm{~h}$ [47-49] Prolonged exposure of parasites to ciprofloxacin increased its anti-malarial activity [47-50]. Additionally, this antibiotic has an in vitro potentiating effect on primaquine by increasing its anti-malarial activity [51]. Chemical modifications of ciprofloxacin by combination of organometallic compounds and a pro-drug approach have been performed to improve its malarial activity [52]. Recently, the graft of a ferrocenic moiety to ciprofloxacin led to an additional enhancement of activity, which could be attributed, first, to oxidative stress due to the redox properties of the ferrocene/ferricenium and, second, to the high lipophilicity of the ferrocene, which may help transport drugs across membranes [53].

With $160 \mathrm{mg} / \mathrm{kg}$, ciprofloxacin was able to prevent mortality of $85 \%$ of mice infected with Plasmodium yoelii [54]. However, the high doses used and the frequent administrations (every $8 \mathrm{~h}$ for 3 days) to achieve effect showed the poor efficacy of ciprofloxacin used alone. Ciprofloxacin was shown to also potentiate the in vivo efficacy of amodiaquine, mefloquine and artemisinin derivatives and chloroquine in mice infected with Plasmodium berghei [55-58].

However, there are some evidences from different clinical trials studies that fluoroquinolones do not have promising results for uncomplicated malaria treatment. In a study conducted in Thailand, oral ciprofloxacin at $750 \mathrm{mg}$ every $12 \mathrm{~h}$ for seven days failed to cure uncomplicated falciparum malaria [59]. Additionally, norfloxacin at $400 \mathrm{mg}$ twice a day for three days cured only $40 \%$ of the patients, while $100 \%$ of the patients treated with chloroquine were cured [60]. It is clear that fluoroquinolones used alone are not a good antimalarial drug and should always be associated with other standard drugs.

The subsequent discovery of an apicoplast in Plasmodium increased interest in further elucidating the mode of action of fluoroquinolones on this parasite [61]. In this context, it has been shown that ciprofloxacin affects $P$. falciparum by causing the formation of an abnormal apicoplast and a 'delayed death' of treated parasites [62]. Quinolones display anti-malarial activity, probably by targeting the gyrase of $P$. falciparum, an enzyme that is involved in apicoplast DNA replication [39, 40]. However, in P. falciparum there is evidence for off-target toxicity, particularly for ciprofloxacin [40]. Ciprofloxacin also reduced the expression of the P. falciparum singlestranded DNA binding protein (PfSSB protein), which plays an essential role in many aspects of nucleic acid metabolism, including DNA replication, recombination and repair [63]. Despite the low activity of fluoroquinolones on malaria parasites, new fluoroquinolone analogues molecules displayed better in vitro activity against $P$. falciparum than ciprofloxacin and synergized the activity of artemisinin [64, 65].

Recent research has demonstrated the promising potential of quinolone analogues as anti-malarial drugs. They show very good efficacy and target several stages of the malaria parasite life cycle, including the erythrocytic, hepatic and gametocytes stages.

Additionally, they present new modes of action that differ from those of most currently used drugs. Compounds with quinolone scaffolds are classified into different structural families: endochin and its analogues, acridinones, haloalkoxyacridinones, carboxyquinolones, $4(1 \mathrm{H})$-quinolones, and quinolone-3-diarylethers.

Anti-malarial property of endochin, synthesized from the nucleus of the quinolones, was first demonstrated on avian malaria in the late 1940s [66]. Further studies on this molecule have established its activity against both hepatic and erythrocytic stages of malaria parasites. However, endochin has proven to be ineffective in vivo against human malaria due to its inactivation by cytochrome P450 enzymes [67]. Endochin analogues targeted the Plasmodium bc $_{1}$ complex at a low nanomolar range, as atovaquone does [68]. New endochin analogues with improved anti-malarial properties were synthesized. The insertion of two fluorine atoms (ELQ121) or one chlorine atom (ELQ-130) in the endochin led to metabolic stability in the presence of cytochrome P450 compared to the parent endochin [67]. The polyethylene glycol of ELQ-121 (ELQ-125) displayed higher oral bio-availability than both endochin and ELQ-121 and cured infected mice with $P$. yoelii at a dose of $50 \mathrm{mg} /$ $\mathrm{kg} /$ day in three days, whereas endochin showed no efficacy [67]. Recently, new substituted compounds based on endochin with a $4(1 H)$-quinolone scaffold displayed activity against multi-drug resistant $P$. falciparum isolates at low nanomolar range. They targeted the Plasmodium $\mathrm{bc}_{1}$ complex without cross-resistance with atovaquone, demonstrated erythrocytic and exoerythrocytic activity and transmission blocking, and improved metabolic stability in the presence of cytochrome P450 [69-74]. Some of these analogues (quinolone-3-diarylethers) were also highly active against Plasmodium vivax isolates [75]. Additionally, hydroxyl-2-dodecyl-4- $(1 H)$ quinolone displayed a dual mechanism of action against two respiratory enzymes, the $P$. falciparum $\mathrm{bc}_{1}$ complex and the $P$. falciparum type II NADH: ubiquinone oxydoreductase (PfNDH2) [76]. Studies were undertaken to identify lead compounds with high activity against PfNDH2. Several 
analogues of quinolones showed the capacity to inhibit PfNDH2 at a low nanomolar range [77, 78].

Tricyclic acridinones are structurally related to quinolones with the 4-oxo-1,4-dihydroquinolone skeleton. Their anti-malarial activity was first reported in 1947 [79]. Other molecules with improved therapeutic properties were later discovered. Because of their poor aqueous solubility and metabolic instability, acridinones were not further evaluated [80]. Recent studies aimed at reevaluating the acridinones which seem promising, with $\mathrm{IC}_{50}<20 \mathrm{nM}$ [81]. Acridinones, like quinolones, targeted the cytochrome $\mathrm{bc}_{1}$ complex and also inhibited haem polymerization, as chloroquine does [82].

Additionally, acridinones blocked the transmission to mosquitoes by preventing oocysts development [72].

The haloalkoxyacridinones are a new class of acridinone [83]. Some of them exhibit extraordinarily strong anti-malarial activity in vitro, with favourable $\mathrm{IC}_{50}$ values of $1 \mu \mathrm{M}$ [84].

Since the discovery of the anti-malarial activity of ICI56-780, a carboxyl derivative of quinolones [85], screening of new compounds has led to the discovery of various 3-carboxyquinolones, which displayed in vitro activity $<100 \mathrm{nM}$ against $P$. falciparum strains and targeted the cytochrome $\mathrm{bc}_{1}$ complex and the dihydroorotate dehydrogenase (DHODH) $[86,87]$.

More research is required to optimize the pharmacodynamic properties of all these derivatives of quinolones. A significant obstacle to the clinical development of these new quinolone analogues is related to their physicochemical properties. Their relatively poor aqueous solubility limits absorption. This implies that only low blood concentrations can be achieved following oral dosing. Prodrug strategy represents a viable approach to improve bio-availability and overcome the physicochemical limitations of quinolone analogues to deliver the active drug at concentrations sufficient for safety, as well as achieving single-dose cures [88]. At the molar equivalent dose of $3 \mathrm{mg} / \mathrm{kg}$ of body weight, the delivery of ELQ-300, a endochin analogue from ELQ-337, its O-linked carbonate ester pro-drug, is enhanced by threefold to fourfold, reaching a maximum concentration of drug in serum [88].

The very good efficacy at nanomolar range against $P$. falciparum and $P$. vivax, their action on several stages of the malaria parasite life cycle, including the erythrocytic, hepatic and gametocytes stages, the new modes of action that differ from those of most currently used drugs demonstrated the promising potential of these new quinolone analogues as anti-malarial drugs to treat malaria. Further studies should be promoted to assess the effects of these new quinolones in combination with artemisinin derivatives and other anti-malarial drugs to find the best partner to use quinolones in combination in malaria treatment (ACT for example).

\section{Tigecycline}

Tigecycline is the lead of a new class of antimicrobials, the glycylcyclines, which belong to the tetracycline class. It is a semi-synthetic derivative of minocycline containing a glycyl amino substitution at position 9 [89]. Tigecycline is highly effective against gram-positive, gram-negative, atypical, anaerobic, and other difficult-to-treat pathogens. This drug is specifically designed to overcome two common mechanisms of tetracycline resistance, namely resistance mediated by acquired efflux pumps and/or ribosomal protection [90]. This tetracycline analogue is not recommended in children and pregnant women. Tigecycline with a twice-daily dosing regimen is generally well tolerated, but because it must be administered intravenously, its use in malaria treatment should be reserved for patients with severe and complicated malaria. The anti-malarial activity of tigecycline was first tested ex vivo on isolates from Bangladesh using the HRP2 ELISA assay [90]. Tigecycline showed significant activity correlation only with doxycycline and not with azithromycin, dihydroartemisinin, chloroquine, quinine, or mefloquine. These results suggested that tigecycline may have a delayed action on malaria parasites, just such as doxycycline, and appeared to be one of the best antibiotics against $P$. falciparum, with an $\mathrm{IC}_{50}$ within the nanomolar range and a relatively steep dose-response curve.

The in vitro activity of this molecule was then studied in clinical isolates of P. falciparum from Gabon [91]. As in the previous study, the activity was compared with that of clindamycin and doxycycline. This study demonstrated the substantial in vitro activity of tigecycline on P. falciparum. Tigecycline appeared to act faster than any other tetracyclines, with the highest activity at day 3 . Meanwhile, the study underlined the limited clinical use of tigecycline due to its pharmacokinetic properties [92], with a risk to expose parasite populations to a prolonged period of subtherapeutic concentrations, thus increasing the risk of resistance.

All these results were confirmed in South America with the evaluation of in vitro antimalarial activity of tigecycline against culture-adapted reference strains and clinical isolates from the Brazilian Amazon [93]. However, all these in vitro studies were performed on a limited number of isolates; in vivo assays and randomized clinical trials are needed to establish the clinical applicability of tigecycline. Moreover, the co-administration of tigecycline with a schizonticide drugs that have a short elimination half-life should be performed to observe a potential synergistic effect. A low dose of $3.7 \mathrm{mg} / \mathrm{kg} /$ day for four days produced a $77-92 \%$ suppression in parasitaemia on 
day 5 after the treatment of mice infected with $P$. berghei. The same report obtained a complete cure of malaria in P. berghei-infected mice with tigecycline $(3.7 \mathrm{mg} / \mathrm{kg} / \mathrm{day})$ in combination with a subcurative dose of chloroquine $(33.3 \mathrm{mg} / \mathrm{kg} /$ day) [94]. These results indicate the promising anti-malarial effect of glycylcyclines in combination with chloroquine and support further in vivo assays and randomized clinical trials.

Because tigecycline must be administered intravenously, its use in malaria treatment should be reserved for patients with severe and complicated malaria. With the emergence of resistance to artesunate and ACT in Southeast Asia [95, 96], tigecycline could be a partner to artesunate in complicated malaria.

\section{Mirincamycin}

Mirincamycin is a lincosamide antibiotic similar to clindamycin that is synthetically produced. This older molecule was studied in 2009 on P. falciparum isolates from Gabon [97]. In this study, the inhibitory activities of cis- and trans-mirincamycin $(3.2$ and $2.6 \mathrm{nM}$, respectively) were compared with the activities of doxycycline $(720 \mathrm{nM})$ and clindamycin $(12 \mathrm{nM})$. The study reported high in vitro activity against clinical $P$. falciparum isolates. $\mathrm{IC}_{50}$ of both isomers were substantially lower than those of any other antibiotic tested so far, including the lincosamide comparator clindamycin [97]. Myrancamycin showed in vitro additive and synergistic effects in combination with tafenoquine, dihydroartemisinin and chloroquine [98]. Furthermore, in Plasmodium cynomolgi infections of rhesus monkeys, mirincamycin was curative as a monotherapeutic regimen and showed an addictive effect when given together with primaquine $[99,100]$. However, the role of mirincamycin on preerythrocytic stages is unclear. It failed to kill hypnozoites in infected rhesus monkeys with P. cynomolgi [101]. At $80 \mathrm{mg} / \mathrm{kg} /$ day for seven days orally, mirincamycin did not prevent relapse in $P$. cynomolgi-infected monkeys while it inhibited pre-erythrocytic development of $P$. cynomolgi at $40 \mathrm{mg} / \mathrm{kg}$ in another study [99]. This might be due to its low oral bio-availability in monkeys $(<15 \%)$ [102]. In these studies, toxicity was reported to be similar to that of clindamycin. After several years, further clinical developments of mirincamycin are being pursued, and the molecule seems to be an interesting partner to fast-acting anti-malarial drugs.

\section{Ketolide agents}

Ketolides are a recent class of macrolide derivative agents characterized by the replacement of the 3-cladinose of the macrolide ring by a keto-group. Ketolides inhibit bacterial growth by interfering with the translation of messenger RNA [103, 104]. These antibiotics present a relatively large antimicrobial spectrum and significantly accumulate in tissues. An in vitro study performed in South Africa determined the anti-plasmodial activity of two ketolide agents, including telithromycin, against chloroquine-susceptible and chloroquineresistant strains of $P$. falciparum (3-15 $\mathrm{nM}$ ) [105]. Telithromycin induced a delayed effect in $P$. falciparum parasites, suggesting its implication in the impairment of the apicoplast translation processes [106]. Cethromycin, a macrolide-quinoline hybrid, at a dose of $12 \mathrm{mg} / \mathrm{kg}$ in combination with primaquine at a dose of $15 \mathrm{mg} / \mathrm{kg}$ showed greater than $99 \%$ P. yoelii elimination on infected mice [107]. Tricyclic ketolides with anti-malarial activity were inhibitors of histone deacetylase protein (HDAC) [108]. These results indicated that, anti-malarial potential of the ketolide antimicrobial agents should further be evaluated.

\section{Fusidic acid}

Fusidic acid is a steroid antibacterial derived from the fungus Fusidium coccineum and used for methicillinresistant Staphylococcus aureus. Its displayed an in vitro anti-malarial activity against $P$. falciparum parasites at concentrations achievable by oral administration [109]. Two studies showed the effect of the elongation factorG (EF-G) inhibitor on the translation apparatus of two malaria parasite organelles (the mitochondrion and the apicoplast) $[110,111]$. Fusidic acid stalls the EF-G/ GDP complex by binding to this complex immediately after GTP hydrolysis and by inhibiting a conformational change required for the release of the factor from the ribosome. The investigation on recombinant apicoplast and mitochondrion of $P$. falciparum showed that inhibition of $P$. falciparum growth in erythrocytes by fusidic acid does not exhibit the classic 'delayed death' phenotype observed for apicoplast-targeted proteins. Indeed, the inhibition of the parasite occurred both in the first as well as the second cycle of infection of $P$. falciparum parasites in blood culture. Secondly, fusidic acid presented a greater inhibitory effect on the apicoplastic EF-G than on the mitochondrial EF-G. However, no clinical trial has been performed to evaluate the efficacy of fusidic acid on P. falciparum infections. Therefore, research for the precise target of such antibiotics is useful when designing future anti-malarial molecules and derivatives.

\section{Thiopeptides: thiostrepton and nocathiacin}

Thiostrepton, a thiazolyl peptide or thiopeptide, is produced by Streptomyces azureus. Micrococcin, another thiopeptide, is produced by Bacillus and Micrococus spp. While thiostrepton displayed $P$. falciparum growth inhibition at a micromolar range, micrococcin acted at a nanomolar range [112, 113]. Thiostrepton exhibited 
gametocytocidal activity and interfered both with apicoplast and parasite proteasome [114-116]. Thiostrepton binds to the $P$. falciparum apicoplast $23 \mathrm{~S}$ rRNA [117, 118]. However, thiostrepton showed effects on mitochondrial protein synthesis [119]. Thiostrepton exerted action on mitochondrial EF-G [110]. This drug could be a candidate against malaria in the future; thus, its mechanism of action needs to be better documented.

Nocathiacin, another thiazolyl peptide, displayed potent activity against a wide spectrum of multidrug resistant gram-positive bacteria and inhibited protein synthesis. A water-soluble derivative of nocathiacin exerted an irreversible growth inhibition within the first growth cycle at a nanomolar range against chloroquinesusceptible and resistant $P$. falciparum strains and was immediately effective [120]. Further investigations need to be done on this drug and its derivatives to understand its mode of action P. falciparum.

\section{Conclusions}

If tetracyclines and macrolides are now well known as anti-malarial drugs, other antibiotics should also be considered. Major discoveries could arise from chemical modifications of older molecules with anti-plasmodial properties.

An advantage of using antibiotics already approved, like doxycycline, tigecycline, clindamycin, azithromycin or co-trimoxazole, as anti-malarial drugs is the reduced cost of clinical development. Additionally, most of the antibiotics already approved are inexpensive and almost universally available. Another advantage is that the modes of action of antibiotics (action on apicoplast, inhibition of type II topo-isomerase enzyme, $P$. falciparum $\mathrm{bc}_{1}$ complex, PfNDH2, DHODH or HDAC) differ from those of most currently used drugs. This difference in modes of action implies that there are not crossresistance between antibiotics and standard anti-malarial drugs. Antibiotics can be used in areas where parasites are resistant to standard anti-malarial drugs. This difference in modes of action also implies that antibiotics can be a good partner for combination. Clindamycin is recommended by the WHO in combination with quinine for the treatment of uncomplicated malaria in pregnant women during the first trimester [121]. Additionally, some of the new antibiotics show synergistic effects in combination with standard anti-malarial drugs: myrancamycin showed in vitro synergistic effects in combination with tafenoquine, dihydroartemisinin and chloroquine [98] and ELQ-300 was highly synergistic with atovaquone in $P$. yoelii murine models [122]. Nevertheless, the greater use of antibiotics against malaria cannot be promoted without considering the risk of the emergence of resistant bacteria. The use of antibiotics for malaria chemoprophylaxis always triggers opposition from a number of bacteriologists, who note the risk of selecting resistant bacteria cyclins [123]. The impact of chemoprophylaxis by doxycycline on bacterial pathogens is the best documented. In 1988, a publication reported tetracycline-resistant cases of Campylobacter jejuni gastroenteritis among American soldiers based in Thailand [124]. A subsequent study by the same team showed that taking doxycycline for malaria prophylaxis resulted in less exposure to resistant bacteria than the acquisition of already resistant s, which has long been widespread in this country [125]. The increase in multidrug-resistant gram-negative bacteria colonization among US military personnel in Afghanistan is likely due to environmental exposures rather than doxycycline exposure [126]. Methicillin-susceptible Staphylococcus aureus and methicillin-resistant Staphylococcus aureus colonization of military personnel under deployment was not associated with doxycycline exposure [127]. However, outbreaks of Panton-Valentine leukocidin-positive, doxycycline resistant, methicillinsusceptible Staphylococcus aureus infections associated with doxycycline prophylaxis have been reported in the French Army at the Ivory Coast [128]. Except for these military clinical cases, no study has been published about the risk of bacterial resistance to tetracyclines associated with their prophylaxis use. In the light of these observations, the impact of malaria chemoprophylaxis with doxycycline on bacteria resistance is not clear. Additionally, microbiome plays an important role in human health. Changes in the microbial flora can promote resistance or infection by pathogenic bacteria. Antibiotics have an impact on the microbiota that can lead to the spread of the pathogen populations [129, 130]. Q fever endocarditis patients treated with doxycycline presented significantly lower concentrations of Bacteroidetes, Firmicutes and Lactobacillus [131]. However, the same observation was found with hydroxychloroquine [131]. However, development of resistance in bacterial pathogens cannot be excluded in wide use of antibiotics for the treatment of uncomplicated malaria. The use in malaria treatment of antibiotics should perhaps be reserved for patients with severe and complicated malaria or patients from special risk groups with uncomplicated malaria. The use of antibiotics should only be considered after reviewing the conclusive results of clinical trials performed on exposed populations from different geographical areas.

\footnotetext{
Abbreviations

ACT: artemisinin-based combination therapy; AIDS: acquired immune deficiency syndrome; DHODH: dihydroorotate dehydrogenase; DNA: deoxyribonucleic acid; EF-G: elongation factor-G; GTP: guanosine triphosphate; HDAC: histone deacetylase protein; HIV: human immunodeficiency virus; HRP2: histidine-rich protein $\mathrm{I}_{\mathrm{i}} \mathrm{IC}_{50}$ : inhibitory concentration 50\%; IPT: intermittent preventive treatment; PfNDH2: P. falciparum type II NADH: ubiquinone
} 
oxydoreductase; PfSSB protein: P. falciparum single-stranded DNA binding protein; RNA: ribonucleic acid; WHO: World Health Organization.

\section{Authors' contributions}

TG, MM, FFT, JD and BP drafted the manuscript. All authors read and approved the final manuscript.

\section{Author details}

'Fédération des Laboratoires, Hôpital d'Instruction des Armées Saint Anne, Toulon, France. ${ }^{2}$ Unité de Parasitologie et d'Entomologie, Département des Maladies Infectieuses, Institut de Recherche Biomédicale des Armées, Marseille, France. ${ }^{3}$ Unité de Recherche sur les Maladies Infectieuses et Tropicales Emergentes, Aix Marseille Université, UM 63, CNRS 7278, IRD 198, Inserm 1095, Marseille, France. ${ }^{4}$ Centre National de Référence du Paludisme, Marseille, France.

\section{Acknowledgements}

Not applicable.

\section{Competing interests}

The authors declare that they have no competing interests.

\section{Funding}

FFT was supported by the Fondation Méditerranée Infection.

Received: 24 June 2016 Accepted: 10 November 2016

Published online: 15 November 2016

\section{References}

1. WHO. World malaria report 2015. Geneva: World Health Organization; 2015.

2. Mita T, Venkatesan M, Ohashi J, Culleton R, Takahashi N, Tsukahara T, et al. Limited geographical origin and global spread of sulfadoxineresistant dhps alleles in Plasmodium falciparum populations. J Infect Dis. 2011:204:1980-8.

3. Wootton JC, Feng X, Ferdig MT, Cooper RA, Mu J, Baruch DI, et al. Genetic diversity and chloroquine selective sweeps in Plasmodium falciparum. Nature. 2002;418:320-3.

4. Tilley L, Straimer J, Gnädig NF, Ralph SA, Fidock DA. Artemisinin action and resistance in Plasmodium falciparum. Trends Parasitol. 2016;32:682-96.

5. Gaillard T, Madamet M, Pradines B. Tetracyclines in malaria. Malar J. 2015;14:445.

6. Gaillard T, Dormoi J, Madamet M, Pradines B. Macrolides and associated antibiotics based on similar mechanism of action like lincosamides in malaria. Malar J. 2016;15:85.

7. Bushby SR, Hitchings $\mathrm{GH}$. Trimethoprim, a sulphonamide potentiator. $\mathrm{Br}$ J Pharmacol Chemother. 1968;33:72-90.

8. Fasan PO. Trimethoprim plus sulphamethoxazole compared with chloroquine in the treatment and suppression of malaria in African school children. Ann Trop Med Parasitol. 1971;65:117-21.

9. WHO. Guidelines on post-exposure prophylaxis for HIV and the use of co-trimoxazole prophylaxis for HIV-related infections among adults, adolescents and children. Recommendations for a public health approach—December 2014 supplement to the 2013 consolidated ARV guidelines. Geneva: World Health Organization; 2014.

10. Manyando C, Njunju EM, D'Alessandro U, Van Geertruyden JP. Safety and efficacy of co-trimoxazole for treatment and prevention of Plasmodium falciparum malaria: a systematic review. PLoS ONE. 2013;8:56916.

11. Suthar AB, Vitoria MA, Nagata JM, Anglaret $X$, Mbori-Ngacha $D$, Sued $\mathrm{O}$, et al. Co-trimoxazole prophylaxis in adults, including pregnant women, with HIV: a systematic review and meta-analysis. Lancet HIV. 2015;2:e137-50.

12. Sowunmi A, Gbotosho GO, Fateye BA, Adedeji AA. Predictors of the failure of treatment with trimethoprim-sulfamethoxazole in children with uncomplicated, Plasmodium falciparum malaria. Ann Trop Med Parasitol. 2006;100:205-11.
13. Mermin J, Ekwaru JP, Liechty CA, Were W, Downing R, Ransom R, et al. Effect of co-trimoxazole prophylaxis, antiretroviral therapy, and insecticide-treated bednets on the frequency of malaria in HIV-1-infected adults in Uganda: a prospective cohort study. Lancet. 2006:367:1256-61.

14. Manyando C, Njunju EM, Mwakazanga D, Chongwe G, Mkandawire R, Champo D, et al. Safety of daily co-trimoxazole in pregnancy in an area of changing malaria epidemiology: a phase $3 \mathrm{~b}$ randomized controlled clinical trial. PLoS ONE. 2014;9:96017.

15. Corbett EL, Churchyard GJ, Charalambos S, Samb B, Moloi V, Clayton TC, et al. Morbidity and mortality in South African gold miners: impact of untreated disease due to human immunodeficiency virus. Clin Infect Dis. 2002;34:1251-8.

16. Hamel MJ, Holtz T, Mkandala C, Kaimila N, Chizani N, Bloland P, et al. Efficacy of trimethoprim-sulfamathoxazole compared with sulfadoxinepyrimethamine plus erythrocyn for the treatment of uncomplicated malaria in children with integrated management of childhood illness dual classifications of malaria and pneumonia. Am J Trop Med Hyg. 2005;73:609-15

17. Sowunmi A, Fateye BA, Ededeji AA, Fehintola FA, Bamgboye AE, Babalola CP, et al. Effects of antifolates-co-trimoxazole and pyrimethamine-sulfadoxine on gametocytes in children with acute, symptomatic, uncomplicated, Plasmodium falciparum malaria. Mem Inst Oswaldo Cruz. 2005;100:451-5.

18. Omar SA, Bakari A, Owiti A, Adagu IS, Warhurst DC. Co-trimoxazole compared with sulfadoxine-pyrimethamine in the treatment of uncomplicated malaria in Kenyan children. Trans R Soc Trop Med Hyg 2001;95:657-60.

19. Duff S, Avery VM. Identification of inhibitors of Plasmodium falciparum gametocyte development. Malar J. 2013;12:408.

20. Nakajanko D, Kiragga AN, Castelnuovo B, Kyabayinze DJ, Kamya MR Low prevalence of Plasmodium falciparum antigenaemia among asymptomatic HAART-treated adults in an urban cohort in Uganda. Malar J. 2011;10:66

21. Gasasira AF, Kamya MR, Ochong EO, Vora N, Achan J, Charlebois E, et al. Effect of trimethoprim-sulphamethoxazole on the risk of malaria in HIVinfected Ugandan children living in an area of widespread antifolate resistance. Malar J. 2010:9:177.

22. Kamya MR, Gasisara AF, Achan J, Mebrahtu T, Ruel T, Kekitiinwa A, et al. Effects of trimethoprim-sulfamethoxazole and insecticide-treated bednets on malaria among HIV-infected Ugandan children. AIDS. 2007:21:2059-66.

23. Mermin J, Lule J, Ekwaru JP, Downing R, Hughes P, Bunnell R, et al. Cotrimoxazole prophylaxis by HIV-infected persons in Uganda reduced morbidity and mortality among HIV-uninfected family members. AIDS. 2005;19:1035-42.

24. Mermin J, Lule J, Ekwaru JP, Malamba S, Downing R, Ransom R, et al. Effect of co-trimoxazole prophylaxis on morbidity, mortality, CD4cell count, and viral load in HIV infection in rural Uganda. Lancet. 2004;364:1428-34.

25. Walker AS, Ford D, Gilks CF, Munderi P, Ssali F, Reid A, et al. Daily cotrimoxazole prophylaxis in severely immunosuppressed HIV-infected adults in Africa started on combination antiretroviral therapy: an observational analysis of the DART cohort. Lancet. 2010;375:1278-86.

26. Thera MA, Sehdev PS, Coulibaly D, Traore K, Garba MN, Cissoko Y, et al. Impact of trimethoprim-sulfamethoxazole prophylaxis on falciparum malaria infection and disease. J Infect Dis. 2005;192:1823-9.

27. Sandison TG, Homsy J, Arinaitwe E, Wanzira H, Kakuru A, Bigira V, et al. Protective efficacy of co-trimoxazole prophylaxis against malaria in HIV exposed children in rural Uganda: a randomised clinical trial. BMJ. 2011;342:1617.

28. Kapito-Tembo A, Meshnick SR, van Hensbroek MB, Phiri K, Fitzgerald M, Mwapasa V. Marked reduction in prevalence of malaria parasitemia and anemia in HIV-infected pregnant women taking cotrimoxazole with or without sulfadoxine-pyrimethamine intermittent therapy during pregnancy in Malawi. J Infect Dis. 2011;203:464-72.

29. Newman PM, Wanzira H, Tumwine G, Arinaitwe E, Waldman S, Achan $J$, et al. Placental malaria among HIV-infected and uninfected women receiving anti-folates in a high transmission area of Uganda. Malar J. 2009:8:254. 
30. Walter J, Mwiya M, Scott N, Kasonde P, Sinkala M, Kankasa C, et al. Reduction in preterm delivery and neonatal mortality after the introduction of antenatal cotrimoxazole prophylaxis among HIV-infected women with low CD4 cell counts. J Infect Dis. 2006;194:1510-8.

31. Iyer JK, Milhous WK, Cortese JF, Kublin JG, Plowe CV. Plasmodium falciparum cross-resistance between trimethoprim and pyrimethamine. Lancet. 2001;358:1066-7.

32. Triglia T, Menting JG, Wilson C, Cowman AF. Mutations in dihydropteroate synthase are responsible for sulfone and sulfonamide resistance in Plasmodium falciparum. Proc Natl Acad Sci USA. 1997;94:13944-9.

33. Malamba S, Sandison T, Lule J, Reingold A, Walker J, Dorsey G, et al. Plasmodium falciparum dihydrofolate reductase and dihyropteroate synthase mutations and the use of trimethoprim-sulfamethoxazole prophylaxis among persons infected with human immunodeficiency virus. Am J Trop Med Hyg. 2010;82:766-71.

34. Malamba SS, Mermin J, Reingold A, Lule JR, Downing R, Ransom $\mathrm{R}$, et al. Effect of cotrimoxazole prophylaxis taken by human immunodeficiency virus (HIV)-infected persons on the selection of sulfadoxine-pyrimethamine-resistant malaria parasites among HIV-uninfected household members. Am J Trop Med Hyg. 2006;75:375-80.

35. Hamel MJ, Greene C, Chiller T, Ouma P, Polyak C, Otieno K, et al. Does cotrimoxazole prophylaxis for the prevention of HIV-associated opportunistic infections select for resistant pathogens in Kenyan adults? Am J Trop Med Hyg. 2008;79:320-30.

36. Fehintola FA. Cotrimoxazole, clinical uses and malaria chemotherapy. Afr J Med Med Sci. 2010;39:63-8.

37. González R, Sevene E, Jagoe G, Slutsker L, Menéndez C. A public health paradox: the women most vulnerable to malaria are the least protected. PLoS Med. 2016;13:e1002014.

38. Lesher GY, Froelich EJ, Gruett MD, Bailey JH, Brundage RP. 1,8-naphthyridine derivatives. A new class of chemotherapeutic agents. J Med Pharm Chem. 1962:91:1063-5.

39. Dubar F, Wintjens R, Martins-Duarte ES, Vommaro RC, Souza W, Dive D, et al. Ester prodrugs of ciprofloxacin as DNA-gyrase inhibitors: synthesis, antiparasitic evaluation and docking studies. Med Chem Commun. 2011;2:430-5

40. Tang Girwood SC, Nenornas E, Shapiro TA. Targeting the gyrase of Plasmodium falciparum with topoisomerase poisons. Biochem Pharmacol. 2015:95:227-37.

41. Beteck RM, Smit FJ, Haynes RK, N'Da DD. Recent progress in the development of anti-malarial quinolones. Malar J. 2014;13:339.

42. Hamzah J, Skinner-Adams T, Davis TME. In vitro antimalarial activity of trovafloxacin, a fourth-generation fluoroquinolone. Acta Trop. 2000;74:39-42.

43. Pradines B, Rogier C, Fusai T, Mosnier J, Daries W, Barret E, et al. In vitro activities of antibiotics against Plasmodium falciparum are inhibited by iron. Antimicrob Agents Chemother. 2001;45:1746-50.

44. Pradines B, Ramiandrasoa F, Rolain JM, Rogier C, Mosnier J, Daries W, et al. In vitro potentiation of antibiotics activities by a catecholate iron chelator against chloroquine-resistant Plasmodium falciparum. Antimicrob Agents Chemother. 2002;46:225-8.

45. Mahmoudi N, Ciceron L, Franetich JF, Farhati K, Silvie O, Eling W, et al. In vitro activities of 25 quinolones and fluoroquinolones against liver and blood stage Plasmodium spp. Antimicrob Agents Chemother. 2003;47:2636-9.

46. Anquetin G, Rouquayrol M, Mahmaoudi N, Santillana-Hayat M, Gozalbes $\mathrm{R}$, Greiner J, et al. Synthesis of new fluoroquinolones and evaluation of their in vitro activity on Toxoplasma gondii and Plasmodium spp. Bioorg Med Chem Lett. 2004;14:2773-6.

47. Krishna S, Davis TME, Chan PCY, Wells RA, Robson KJH. Ciprofloxacin and malaria. Lancet. 1988;1:1231-2.

48. Divo AA, Sartorelli AC, Patton CL, Bia FJ. Activity of fluoroquinolone antibiotics against Plasmodium falciparum in vitro. Antimicrob Agents Chemother. 1988;32:1182-6.

49. Goodman CD, Su V, McFadden Gl. The effects of anti-bacterials on the malaria parasite Plasmodium falciparum. Mol Biochem Parasitol. 2007:152:181-91.

50. Yeo AE, Rieckmann KH. Prolonged exposure of Plasmodium falciparum to ciprofloxacin increases anti-malarial activity. J Parasitol. 1994;80:158-60.
51. Soares RPP, Krettli AU, de Souza MVN, Vasconcelos TRA, Boechat N. Evaluation of antimalarial and fluoroquinolone combinations against Plasmodium falciparum in vitro. Int J Antimicrob Agents. 2006;28:270-2.

52. Dubar F, Anquetin G, Pradines B, Dive D, Khalife J, Biot C. Enhancement of the antimalarial activity of ciprofloxacin using a double prodrug/ bioorganometallic approach. J Med Chem. 2009;52:7954-7.

53. Dubar F, Egan TJ, Pradines B, Kuter D, Ncokazi KK, Forge D, et al. The antimalarial ferroquine: role of the metal and intramolecular hydrogen bond in activity and resistance. ACS Chem Biol. 2011;6:275-87.

54. Salmon D, Deloron P, Gaudin C, Malhotra K, Lebras J, Pocidalo JJ. Activities of pefloxacin and ciprofloxacin against experimental malaria in mice. Antimicrob Agents Chemother. 1990;34:2327-30.

55. Falajiki YF, Akinola O, Abiodun OO, Happi CT, Sowunmi A, Gbotosho GO Amodiaquine-ciprofloxacin: a potential combination therapy against drug resistant malaria. Parasitology. 2015;142:849-54.

56. Ubulom PME, Udobi CE, Madu MI. Amodiaquine and ciprofloxacin combination in plasmodiasis therapy. J Trop Med. 2015;2015:947390.

57. Andrade AA, de Pilla Varoti F, de Freitas IO, de Souza MVN, Vasconcelos TRA, Boechat N, et al. Enhanced activity of mefloquine and artesunic acid against Plasmodium falciparum in vitro and $P$. berghei in mice by combination with ciprofloxacin. Eur J Pharmacol. 2007;558:194-8.

58. Olusola Gbotosho G, Happi CT, Woranola O, Abiodun OO, Sowunmi A Oduola AM. Interaction between ciprofloxacin and chloroquine in mice infected with chloroquine resistant Plasmodium berghei. Parasitol Res. 2012;110:895-9.

59. Watt G, Shanks GD, Edstein MD, Pavanand K, Webster HK, Wechgritaya S. Ciprofloxacin treatment of drug-resistant falciparum malaria. J Infect Dis. 1991;164:602-4.

60. McClean KL, Hitchman D, Shafran SD. Norfloxacin is inferior to chloroquine for falciparum malaria in northwestern Zambia: a comparative clinical trial. J Infect Dis. 1992;165:904-7.

61. Maréchal E, Cesbron-Delauw MF. The apicoplast: a new member of the plastid family. Trends Plant Sci. 2001;6:200-5.

62. Dahl EL, Rosenthal PJ. Multiple antibiotics exert delayed effects against the Plasmodium falciparum apicoplast. Antimicrob Agents Chemother. 2007;51:3485-90

63. Prusty D, Dar A, Priya R, Sharma A, Dana S, Choudhury NR, et al. Single-stranded DNA binding protein from human malaria parasite Plasmodium falciparum is encoded in the nucleus and targeted to the apicoplast. Nucleic Acids Res. 2010;38:7037-53.

64. Dixit SK, Mishra N, Sharma M, Singh S, Agarwal A, Awasthi SK, et al. Synthesis and in vitro antiplasmodial activities of fluoroquinolone analogs. Eur J Med Chem. 2012;51:52-9.

65. Agarwal D, Sharma M, Dixit SK, Dutta RK, Singh AK, Gupta RD, et al. In vitro synergistic effect of fluoroquinolone analogues in combination with artemisinin against Plasmodium falciparum; their antiplasmodial action in rodent malaria model. Malar J. 2015;14:48.

66. Salzer W, Timmler H, Andersag $\mathrm{H}$. A new type of compound active against avian malaria. Eur J Inorg Chem. 1948;81:12-9.

67. Winter R, Kelly JX, Smilkstein MJ, Hinrichs D, Koop DR, Riscoe MK. Optimization of endochin-like quinolones for antimalarial activity. Exp Parasitol. 2011;127:545-51.

68. Winter RW, Kelly JX, Smilkstein MJ, Dodean R, Hinrichs D, Riscoe MK Antimalarial quinolones: synthesis, potency, and mechanistic studies. Exp Parasitol. 2008;118:487-97.

69. Cross RM, Flanigan DL, Monastyrskyi A, LaCrue AN, Sáenz FE, Maignan $J R$, et al. Orally bioavailable 6-chloro-7-methoxy-4(1H)-quinolones efficacious against multiple stages of Plasmodium. J Med Chem. 2014:57:8860-79.

70. Monastyrskyi A, Kyle D, Manetsch R. 4(1H)-pyridone and 4(1H)quinolone derivatives as antimalarials with erytrocytic, exoerythrocytic, and transmission blocking activities. Curr Top Med Chem. 2014;14:1693-705.

71. Rodrigues T, Ressurreiçao AS, da Cruz FP, Albuquerque IS, Gut J, Carrasco MP, et al. Flavones as isosteres of $4(1 H)$-quinolones: discovery of ligand efficient and dual stage antimalarial lead compounds. Eur J Med Chem. 2013;69:872-80.

72. Saenz FE, LaCrue AN, Cross RM, Maignan JR, Udenze KO, Manetsch R, et al. 4-(1H)-quinolones and 1,2,3,4-tetrahydroacridin-9(10H)-ones prevent the transmission of Plasmodium falciparum to Anopheles freeborni. Antimicrob Agents Chemother. 2013;57:6187-95. 
73. Saleh A, Friesen J, Baumeister S, Gross U, Bohne W. Growth inhibition of Toxoplasma gondii and Plasmodium falciparum by nanomolar concentrations of 1-hydroxy-2-dodecyl-4(1H)quinolone, a high-affinity inhibitor of alternative (type II) NADH dehydrogenases. Antimicrob Agents Chemother. 2007;51:1217-22.

74. Cross RM, Namelikonda NK, Mutka TS, Luong L, Kyle DE, Manetsch R. Synthesis, antimalarial activity, and structure-activity relationship of 7-(2-phenoxyethoxy)-4(1H)-quinones. J Med Chem. 2011;54:8321-7.

75. Nilsen A, LaCrue AN, White KL, Forquer IP, Cross RM, Marfurt J, et al. Quinolone-3-diarylethers: a new class of drugs for a new era of malaria eradication. Sci Transl Med. 2013;5:177.

76. Biagini GA, Fisher N, Shone AE, Mubaraki MA, Srivastava A, Hill A, et al. Generation of quinolone antimalarials targeting the Plasmodium falciparum mitochondrial respiratory chain for the treatment and prophylaxis of malaria. Proc Natl Acad Sci USA. 2012;109:8298-303.

77. Leung SC, Gibbons P, Amewu R, Nixon GL, Pidathala C, Hong WD, et al. identification, design and biological evaluation of heterocyclic quinolones targeting Plasmodium falciparum type II NADH:quinone oxidoreductase (PfNDH2). J Med Chem. 2012;55:1844-57.

78. Pidathala C, Amewu R, Pacorel B, Nixon GL, Gibbons P, Hong WD, et al. Identification, design and biological evaluation of bisaryl quinolones targeting Plasmodium falciparum type II NADH:quinone oxidoreductase (PfNDH2). J Med Chem. 2012;55:1831-43.

79. Stephen J, Tonkin I, Walker J. Tetrahydroacridones and related compounds as antimalarials. J Chem Soc. 1947;10:1034-9.

80. Kesten SJ, Degnan MJ, Hung J, McNamara DJ, Ortwine DF, Uhlendorf $\mathrm{SE}$, et al. Synthesis and antimalarial properties of 1-imino derivatives of 7-chloro-3-substituted-3,4-dihydro-1,9(2 $\mathrm{H}, 1 \mathrm{H})$-acridinediones and related structures. J Med Chem. 1992;35:3429-47.

81. Cross RM, Maignan JR, Mutka TS, Luong L, Sargent J, Kyle DE, et al. Optimization of 1,2,3,4-tetrahydroacridin-9(10H)-ones as antimalarials utilizing structure-activity and structure-property relationships. J Med Chem. 2011;54:4399-426.

82. Fernández-Calienes A, Pellon R, Docampo M, Fascio M, D’Accorso N, Maes $L$, et al. Antimalarial activity of new acridinone derivatives. Biomed Pharmacother. 2011;65:210-4.

83. Aymé F. Acridine and acridinones: old and new structures with antimalarial activity. Open J Med Chem. 2011;5:11-20.

84. Winter RW, Kelly JX, Smilkstein MJ, Dodan R, Bagby GC, Rathbun RK, et al. Evaluation and lead optimization of anti-malarial acridones. Exp Parasitol. 2006;114:47-56.

85. Ryley JF, Peters W. The antimalarial activity of some quinolone esters. Ann Trop Med Parasitol. 1970;64:209-22.

86. Zhang Y, Guiguemde WA, Sigal M, Zhu F, Connelly MC, Nwaka S, et al. Synthesis and structure-activity relationships of antimalarial 4-oxo3-carboxyl quinolones. Bioorg Med Chem. 2010;18:2756-66.

87. Zhang Y, Clark JA, Connelly MC, Zhu F, Min J, Guiguemde WA, et al. Lead optimization of 3-carboxyl-4(1H)-quinolones to deliver orally bioavailable antimalarials. J Med Chem. 2012;55:4205-19.

88. Miley GP, Pou S, Winter R, Nilsen A, Li Y, Kelly JX, et al. ELQ-300 prodrugs for enhanced delivery and single-dose cure of malaria. Antimicrob Agents Chemother. 2015;59:5555-60.

89. Olson MW, Ruzin A, Feyfant E, Rush TS, O'Connell J, Bradford PA. Functional, biophysical, and structural bases for antibacterial activity of tigecycline. Antimicrob Agents Chemother. 2006;50:2156-66.

90. Starzengruber P, Thriemer K, Haque R, Khan WA, Fuehrer HP, Siedl A, et al. Antimalarial activity of tigecycline, a novel glycylcycline antibiotic. Antimicrob Agents Chemother. 2009;53:4040-2.

91. Held J, Zanger P, Issifou S, Kremsner PG, Mordmüller B. In vitro activity of tigecycline in Plasmodium falciparum culture-adapted strains and clinical isolates from Gabon. Int J Antimicrob Agents. 2010;35:587-9.

92. Agwuh KN, MacGowan A. Pharmacokinetics and pharmacodynamics of the tetracyclines including glycylcyclines. J Antimicrob Chemother. 2006;58:256-65

93. Ribatski-Silva D, Bassi CL, Martin TOG, Alves-Junior E, Gomes LT, Fontes CJF. In vitro antimalarial activity of tigecycline against Plasmodium falciparum culture-adapted reference strains and clinical isolates from the Brazilian Amazon. Rev Soc Bras Med Trop. 2014;47:110-2.

94. Sahu R, Walker LA, Tekwani BL. In vitro and in vivo anti-malarial activity of tigecycline, a glycylcycline antibiotic, in combination with chloroquine. Malar J. 2014;13:414.
95. Dondorp AM, Nosten F, Yi P, Das D, Phyo AP, Tarning J, et al. Artemisinin resistance in Plasmodium falciparum malaria. N Engl J Med. 2009;361:455-67.

96. Ashley EA, Dhorda M, Fairhurst RM, Amaratunga C, Lim P, Suon S, et al. Spread of artemisinin resistance in Plasmodium falciparum malaria. $N$ Engl J Med. 2015;371:411-23.

97. Held J, Westerman R, Kremsner PG, Mordmüller B. In vitro activity of mirincamycin (U24729A) against Plasmodium falciparum isolates from Gabon. Antimicrob Agents Chemother. 2010;54:540-2

98. Starzengruber P, Fuehrer HP, Swoboda P, Ganesh D, Haque R, Khan WA, et al. Mirincamycin, an old candidate for malaria combination treatment and prophylaxis in the 21st century: in vitro interaction profiles with potential partner drugs in continuous culture and field isolates. Malar J. 2014;13:228.

99. Schmidt LH, Harrison J, Ellison R, Worcester P. The activities of chlorinated lincomycin derivatives against infections with Plasmodium cynomolgi in Macaca mulatta. Am J Trop Med Hyg. 1970;19:1-11.

100. Schmidt LH. Enhancement of the curative activity of primaquine by concomitant administration of mirincamycin. Antimicrob Agents Chemother. 1985:27:151-7.

101. Fracisco S, Teja-isavadharm P, Gettayacamin M, Berman J, Li Q, Melendez $\checkmark$, et al. Anti-relapse activity of mirincamycin in the Plasmodium cynomolgi sporozoite-infected Rhesus monkey model. Malar J. 2014;13:409.

102. Khemawoot P, Saunders D, Rasameesoraj M, Melendez V, Imerbsin R, Ohrt C, et al. Absolute bioavailability of cis-mirincamycin and transmirincamycin in healthy rhesus monkeys and ex vivo antimalarial activity against Plasmodium falciparum. Antimicrob Agents Chemother. 2011;55:5881-6.

103. Douthwaite S, Champney WS. Structures of ketolides and macrolides determine their mode of interaction with the ribosomal target site. J Antimicrob Chemother. 2001:48:1-8.

104. Vazifeh D, Abdelghaffar H, Labro MT. Cellular accumulation of the new ketolide RU 64004 by human neutrophils: comparison with that of azithromycin and roxithromycin. Antimicrob Agents Chemother. 1997:41:2099-107.

105. Makgatho M, Maimela E, Mbajiorgu F. Ketolide agents HMR 3004 and HMR 3647 (telithromycin) inhibit the growth of Plasmodium falciparum in vitro. Afr Health Sci. 2015;15:1271-6.

106. Barthel D, Schlitzer M, Pradel G. Telithromycin and quinupristin induce delayed death in Plasmodium falciparum. Antimicrob Agents Chemother. 2008;52:774-7.

107. Sullivan DJ, Liu Y, Mot BT, Kaludov N, Martinov MN. Discovery of novel liver-stage antimalarials through quantum similarity. PLOS ONE. 2015;10:125593.

108. Mwakwari SC, Guerrant W, Patil V, Khan SI, Tekwani BL, Gurard-Levin ZA, et al. Non-peptide macrocyclic histidine deacethylase inhibitors derived from tricyclic ketolide skeleton. J Med Chem. 2010;53:6100-11.

109. Black FT, Wildfang IL, Borgbjerg K. Activity of fusidic acid against Plasmodium falciparum in vitro. Lancet. 1985;325:578-9.

110. Gupta A, Mir SS, Saqib U, Biswas S, Vaishya S, Srivastava K, et al. The effect of fusidic acid on Plasmodium falciparum elongation factor $G$ (EF-G). Mol Biochem Parasitol. 2013;192:39-48.

111. Johnson RA, McFadden Gl, Goodman CD. Characterization of two malaria parasite organelle translation Elongation Factor G proteins: the likely targets of the anti-malarial fusidic acid. PLOS ONE. 2011;6:20633.

112. McConkey GA, Rogers MJ, McCutchan TF. Inhibition of Plasmodium falciparum protein synthesis. Targeting the plastid-like organelle with thiostrepton. J Biol Chem. 1997;272:2046-9.

113. Rogers MJ, Cundliffe E, McCutchan TF. The antibiotic micrococcin is a potent inhibitor of growth and protein synthesis in the malaria parasite. Antimicrob Agents Chemother. 1998;42:715-6.

114. Delves MJ, Ruecker A, Straschil U, Lelièvre J, Marques S, Lopez-Barragan $\mathrm{MJ}$, et al. Male and female Plasmodium falciparum mature gamatocytes show different responses to antimalarial drugs. Antimicrob Agents Chemother. 2013;57:3268-75.

115. Miguel-Blanco C, Lelièvre J, Delves MJ, Bardera Al, Presa JL, LopezBarragan MJ, et al. Imaging-based high-throughput screening assay to identify new molecules with transmission-blocking potential against Plasmodium falciparum female gamete formation. Antimicrob Agents Chemother. 2015;59:3298-305. 
116. Aminake MN, Schoof S, Sologub L, Leubner M, Kirschner M, Arndt HD, et al. Thiostrepton and derivatives exhibit antimalarial and gametocytocidal activity by dually targeting parasite proteasome and apicoplast. Antimicrob Agents Chemother. 2011;55:1338-48.

117. Clough B, Strath M, Preiser P, Denny P, Wilson I. Thiostrepton binds to malarial plastid rRNA. FEBS Lett. 1997;406:123-5.

118. Rogers MJ, Bukhman YV, McCutchan TF, Draper DE. Interaction of thiostrepton with an RNA fragment derived from the plastid-encoded ribosomal RNA of the malaria parasite. RNA. 1997;3:815-20.

119. Tarr SJ, Nisbet RER, Howe CJ. Transcript-level responses of Plasmodium falciparum to thiostrepton. Mol Biochem Parasitol. 2011;179:37-41.

120. Sharma I, Sullivan M, McCutchan TF. The in vitro anti-malarial activity of novel semi synthetic nocathiacin I antibiotics. Antimicrob Agents Chemother. 2015;59:3174-9.

121. WHO. Guidelines for the treatment of malaria. 3rd ed. Geneva: World Health Organization; 2015.

122. Stickles AM, Smilkstein MJ, Morrisey JM, Li Y, Forquer IP, Kelly JX, et al. Atovaquone and ELQ-300 combination therapy as a novel dual-site cytochrome bc1 inhibition strategy for malaria. Antimicrob Agents Chemother. 2016;60:4853-9.

123. Chopra I, Roberts M. Tetracycline antibiotics: mode of action, applications, molecular biology, and epidemiology of bacterial resistance. Microbiol Mol Biol Rev. 2001;65:232-60.

124. Taylor DN, Pitarangsi C, Echeverria P, Diniega BM. Campylobacter enteritis during doxycycline prophylaxis for malaria in Thailand. Lancet. 1988;2:578-9.
125. Arthur JD, Echeverria P, Shanks GD, Karwacki J, Bodhidatta L, Brown JE. A comparative study of gastrointestinal infections in United States soldiers receiving doxycycline or mefloquine for malaria prophylaxis. Am J Trop Med Hyg. 1990;43:608-13.

126. Vento TJ, Cole DW, Mende K, Calvano TP, Rini EA, Tully C, et al. Multidrugresistant fram-negative bacteria colonization of healthy US military personnel in the US and Afghanistan. BMC Infect Dis. 2013;13:68.

127. Vento TJ, Cole DW, Mende K, Calvano TP, Rini EA, Tully C, et al. Staphylococcus aureus colonization of healthy military service members in the United States and Afghanistan. BMC Infect Dis. 2013;13:325.

128. Lesens O, Haus-Cheymol R, Dubrous P, Verret C, Spiegel A, Bonnet R, et al. Methicillin-susceptible, doxycycline-resistant Staphylococcus aureus, Côte d'Ivoire. Emerg Infect Dis. 2007;13:488-90.

129. Angelakis E, Merhej $V$, Raoult D. Related actions of probiotics and antibiotics on gut microbiota and weight modification. Lancet Infect Dis. 2013;13:889-99.

130. Bäumler AJ, Sperandio V. Interactions between the microbiota and pathogenic bacteria in the gut. Nature. 2016;535:85-93.

131. Angelakis E, Million M, Kankoe S, Lagier JC, Armougom F, Giorgi R, et al. Abnormal weight gain and gut microbiota modifications are side effects of long-term doxycycline and hydroxychloroquine treatment. Antimicrob Agents Chemother. 2014;58:3342-7.

\section{Submit your next manuscript to BioMed Central and we will help you at every step:}

- We accept pre-submission inquiries

- Our selector tool helps you to find the most relevant journal

- We provide round the clock customer support

- Convenient online submission

- Thorough peer review

- Inclusion in PubMed and all major indexing services

- Maximum visibility for your research

Submit your manuscript at www.biomedcentral.com/submit 